\title{
A Bibliometric Analysis of an International Research Ethics TraineE Program
}

JONATHAN FIX

University of Maryland

JeRE OdeLL

Indiana University-Purdue University

BARBARA Sina

National Institutes of Health

ERIC M. MesLin

Indiana University School of Medicine

Ken Goodman

University of Miami Medical School

Ross UpSHUR

University of Toronto

\begin{abstract}
WE USED BIBLIOMETRIC ANALYSIS TO evaluate the citations associated with publications by trainees in the Fogarty International Center's International Research Ethics Education and Curriculum Development program. Papers published between 2004 and 2008 were identified for analysis. The outcome measures were total citations, h-index, and i-10. A total of 328 manuscripts were identified, with a yearly average of 66 publications and 363 citations. The median number of citations per paper is 3 (IQR Q1-Q3:6). $12.6 \%(n=53)$ of papers were cited over 10 times and the h-index is 22 , indicating that 22 papers had been cited at least 22 times. The data indicate that trainees have been productive and contributed to the scholarly literature. Future studies to benchmark this performance with other bioethics education programs are required to make interpretation of citation analysis more meaningful.
\end{abstract}

KEY WORDS: bioethics education, bioethics scholarship, bibliometrics, citation analysis

Received: June 17, 2013; revised: October 31, 2013

$\mathrm{T}$ He PURPOSE OF THE FOgARTY INTERNAtional Center's (FIC) International Research Ethics Education and Curriculum Development Award is to develop curricula and provide educational opportunities for developing country academics, researchers, and health professionals in ethics related to performing research involving human subjects in resource-poor settings. The goal of this initiative is to increase the number of developing-country scientists, health professionals, and relevant academics with indepth knowledge of the ethical considerations, concepts, and applications in clinical and public health research. The program commenced in 2000. In 2012 there were 21 funded FIC Training Programs, reflecting a commitment to Low and Middle Income Country (LMIC) bioethics training that is unique in the world. Since the beginning of the program, long-term training in bioethics has been given to approximately 600 individuals.

It is expected that such training will enhance the career development of individuals from developing countries, as well as strengthen and sustain the capacity to support ethical clinical and public health research in their home institutions and countries. The focus of the program is not primarily on the development of scientists or a cadre of principal investigators. Nevertheless, it is encouraged and desirable that trainees contribute to bioethics scholarship, especially given the underrepresentation of LMIC voices in the bioethics literature. Here we present an analysis of this scholarship.

Bibliometrics is a set of quantitative methods and techniques to measure scholarly productivity and impact. One of the most common methods of bibliometric assessment of impact is citation analysis, which measures the number of times a paper, author, or organization has been cited in the scholarly literature. Likewise, citation analysis is also used to study patterns in scholarly communications as evidenced by citation between authors, domains of knowledge, and organizations. There is great variability among academic disciplines in the use of citation analysis. It plays a significant role in biosciences and physical sciences, where citation analysis and impact factor are used to compare the influence of scientists and journals.

Disciplines such as bioethics have a less-developed literature in terms of evaluating impact through citation analysis, in part because consensus has not been fully realized about whether bioethics is a discrete discipline or a collection of disciplines. Bioethicists, however, do 
conduct and publish systematic reviews. Not unlike other fields, these have been used to assess the accumulated knowledge about a specific topic, for example, stem cell research (Zarzeczny \& Caulfield, 2009), biobanks (Wendler, 2006), or end-of-life care (Rietjens et al., 2012). From time to time, the scholars conducting these reviews have used bibliometric methods to describe the content and scope of the literature on a topic, or the nature of the ethics literature within a journal or country (Baldwin et al., 2003; Belinchon, Ramos, \& Bellver, 2007; Borry, Schotsmans, \& Dierickx, 2005, 2006a, 2006b; Cohen et al., 2008; Dos Santos \& de France, 2011; Hossne, 2011; Jiang et al., 2012; Marques, de Sousa, \& Gimenez Galvao, 2006; Pizzani, da Silva, \& Hossne, 2010; Stepke, 2010). Scholars have also used bibliometric methods to measure compliance with research ethics regulations and to trace the life cycle of scientific misconduct (Dagg \& Seidle, 2004; Garfield \& WelljamsDorof, 1990; Korpela, 2010; Neale, Dailey, \& Abrams, 2010; Neale et al., 2007; Steen, 2012). There are few published bibliometric studies in bioethics literature and none evaluating the scholarship arising from international bioethics training programs.

The objectives of this study were to employ bibliometric analysis to:

1. Measure the productivity of FIC trainees in terms of published journal articles in bioethics.

2. Determine the citation rates of FIC bioethics publications from 2004 to 2008.

3. Calculate other citation metrics of FIC publications (i-10, h-index over the study period).

4. Compare the differences among citation databases for these publications.

\section{Methods}

A comprehensive database of publications was created by extracting publications by trainees identified in the annual progress reports submitted by principal investigators and renewal applications to the FIC. Data was collected from manuscripts published by trainees between 2004 and 2008. This period was justified on the grounds that by 2004 a sufficient cohort of trainees would have had the opportunity to publish and citations counts would be detectable. Trainees are typically in the program 1-2 years. There were only a small number of publications in the early years of the training program (2000-2004). We also assumed that the number of citations accumulated from papers published after 2008 would be relatively small and comparisons between cohorts not informative. Therefore it was concluded that the most representative frame of the training programs was the cohort from 2004-2008.

Principal Investigators were contacted with a list of publications attributed to their trainees to determine accuracy and comprehensiveness. Duplicates on the list and publications that were clearly not journal articles (e.g., monographs, reports, and book chapters) were removed. Each publication was assessed for relevance to the study and clearly identified as a bioethics paper by members of the research team. This was achieved by examining the title and abstract of the paper to determine if the explicit focus of the paper was bioethical in nature.

Google Scholar, Scopus, and Web of Science were searched for each unique publication. The number of citations for each data source was recorded. Citations from Google Scholar were exported with the use of Zotero and then imported to EndNote. Citations from Scopus and Web of Science were exported with EndNote. A consolidated EndNote database was then created and duplicate entries removed.

Trainees were identified by comparing the author list of each manuscript with the list of trainees provided by the PIs from the funded Fogarty bioethics programs. Each identified trainee was assigned a place in the authorship list (first, second, third, etc.). For publications with multiple authors, and thus, possibly multiple trainees, only the first listed trainee author was recorded.

The numbers of papers with citations, papers found with zero citations, and papers listed by a PI but not found in the databases reviewed, were all calculated summing the overall number of citations count from the citation databases (Google Scholar, Web of Science, Scopus).

The following publication metrics were calculated: mean and median number of citations per publication, h-index, and i- 10 .

The average number of citations for each database was calculated by dividing the total number of citations found by the total number of publications identified that year. Similarly, the median number of citations was derived by analyzing the citation distributions of all papers in the data set according to standard methods of calculating the median and interquartile range. Averages, median, range, and IQR were all calculated using the Excel 2007 tools.

The Hirsch index (h-index) is a commonly employed citation metric that calculates a measure of the cumulative impact of work. For example, if a scientist has an h-index of 30, it means that at least 30 papers the scientist has published have received at least 30 citations. The i- 10 measures the number of papers that have been cited at least 10 times. 
The h-index and i-10 list were calculated by rank ordering the overall list of publications by number of citations, and identifying the appropriate cut points.

\section{Results}

Table 1 reports the number of publications overall and the percentage of papers cited. Between 2004 and 2008 328 manuscripts were identified with a yearly average of 66 publications and 363 citations. The median number of citations per paper is 3 (IQR Q1-Q3:6). 12.6\% $(n=53)$ of papers were cited over 10 times and the h-index is 22 , indicating that 22 papers had been cited at least 22 times.

Table 2 describes the citation analysis. The median number of citations was 3 (range $0-150$ ). There was considerable variability in the number of citations found in each index, with Google Scholar consistently identifying the most citations and Web of Science the fewest.

Table 3 shows the analysis of the data by year and includes a description of the authors. There was consistent production of trainee publications on an annual basis. The number of citations fluctuated over the five years analyzed. Trainees identified as first authors declined over the years examined in the study.

Table 4 shows the top eight journals in which trainee papers were published. The journals encompass nonEnglish language, English language, national and regional specialized bioethics journals, and international "high impact" journals.

\section{Discussion}

This study is the first systematic bibliometric analysis of the scholarly output and impact of an international bioethics training program. The results show consistent scholarly output and citation rates during the years 2004-2008. Few studies have used citation analysis to measure and describe the impact of scholarship in bioethics. In an examination of a curriculum to improve the information skills of medical students, Dorsch (1997) accounted for the use of bioethics journals in student coursework. In mapping the topic of neuroethics, Garnett et al. (2011) studied the citation patterns between ethics authors and those who are publishing literature about fMRI research and medicine. Soós (2006) studied the citation patterns between a list of journals in "science ethics." Holm and William-Jones (2006) analyzed a series of papers from 1995 to 1997 and measured the international scope of bioethics by studying web-links, citation patterns and journal subscriptions; the authors found that the citation record does not yet identify bioethics as a "global field." An analysis by Eiseman (2003) of the influential U.S. National Bioethics Advisory Commission reported 82 citations of NBAC reports in the academic literature for the period 1996-2001, but acknowledged that impact of this type of scholarship (advisory committee reports) ought not to be limited to citations in the peer-reviewed literature.

The data reveal several trends. It is instructive to note a high proportion of trainees as first authors in this cohort. In addition, the number of trainees listed as authors increased over the period studied. The proportion of trainees reported as first authors decreased slightly over the study period from $83 \%$ to $69 \%$. This trend is difficult to interpret. It may represent statistical variability. Further research is needed to clarify whether this finding represents a meaningful trend and to determine whether there are disincentives or barriers to trainees serving as first authors of manuscripts. Borry et al., in their 2006 analysis of nine bioethics journals from 1997 to 2003 , found $96.1 \%$ first authors came from high-income countries. One outcome of the FIC training program may be to aid in redressing this imbalance. This study included a more comprehensive list of journals than the Borry et al. study.

The results also point out gaps in coverage by the major scholarly indexes. There are fewer citations for papers published in languages other than English, illustrating a global problem with journal abstraction practices. It is worth noting that the percentage of papers not found in the databases declined over the study period from $44 \%$ to $23 \%$, indicating improvements of coverage of the bioethics literature. Borry et al. (2006) noted that LMIC countries are underrepresented in the bioethics literature. They cited language barriers, lack of health research funding, lack of access to international journals and editorial bias. Many editorial boards of major bioethics journals are in English-speaking countries, and data show that location of editorial office affects geographic origin of publications. Significantly, many trainees have published in non-English language journals (see examples in Table 4). An increasing number

TABLE 1. Total Publications and \% Cited.

\begin{tabular}{lccc}
\hline Total Publications & \% Cited & $\begin{array}{c}\text { \% Found in Databases } \\
\text { but Not Cited }\end{array}$ & $\begin{array}{c}\text { \% Not Found } \\
\text { in Databases }\end{array}$ \\
\hline 328 & 55 & 14 & 31 \\
\hline
\end{tabular}


TABLE 2. Overall Citation Data.

\begin{tabular}{lccc}
\hline Median Citation (IQR) & Range & H-Index & $\mathrm{i}-10$ \\
\hline 3 (IQR Q1-Q3=6) & $0-150$ & 22 & 53 \\
\hline
\end{tabular}

of bioethics journals are published in LMICs, including open access journals, which indicates growth in potential publication opportunities.

The results also show considerable variability of citation numbers by citation databases. As has been demonstrated in other studies, Google Scholar consistently identified more unique citations for this data set than did the other citation databases (Bauer \& Bakkalbasi, 2005; Harzing \& Van der Wal, 2007; Kulkarni et al., 2009). Clearly, the perceived impact of a paper in terms of citations will vary depending on which data sources are accessed. Reliance on citation indexes that do not include journals likely to publish bioethics papers would underestimate the impact of papers.

It is not possible to compare the Hirsch and i-10 indexes to other bioethics programs as such data do not exist. The h-index is used frequently in bibliometric analysis as a measure of impact. Hirsch created the index to compare productivity of physicists but held that it could be applied to other scientific disciplines and to programs as well as individual scientists. Variability in the h-index by academic discipline has been noted, with higher h-indexes found by researchers in the life sciences as compared to physics mathematics and engineering (Hirsch, 2005; Lillquist \& Green, 2010). Hirsch noted in his original paper that disciplines with large numbers of researchers and intense research activity will have higher citation rates. This is also reflected in the impact factors of journals where specialized and subspecialized journals typically have lower impact factors and citation rates than broad higher impact journals. Bioethics journals typically have low impact factors reflecting the specialized nature of the field.

These study results are subject to several limitations. Only journal articles were included in the analysis, not monographs, book chapters, or reports. In some academic traditions, monographs and book chapters are accorded equal or higher prestige than journal articles. Google Scholar permits easier identification of citations in books and book chapters, so comparison across databases is not possible. Reports are often influential in

TABLE 3. Analysis by Year.

\begin{tabular}{|c|c|c|c|c|c|}
\hline Year & 2004 & 2005 & 2006 & 2007 & 2008 \\
\hline $\begin{array}{l}\text { Number of Publica- } \\
\text { tions }\end{array}$ & 64 & 66 & 69 & 64 & 65 \\
\hline $\begin{array}{l}\text { Number of Fellow } \\
\text { Authors }\end{array}$ & 34 & 35 & 41 & 41 & 45 \\
\hline \multirow[t]{6}{*}{ Role of Fellow } & $1^{\text {st }}$ author: & $1^{\text {st }}$ author: & $1^{\text {st }}$ author: & $1^{\text {st }}$ author: & $1^{\text {st }}$ author: \\
\hline & $53 / 64(82.8 \%)$ & $53 / 66(80.3 \%)$ & $61 / 69(88.4 \%)$ & $47 / 64(73.5 \%)$ & $45 / 65(69.2 \%)$ \\
\hline & $2^{\text {nd }}$ author: & $2^{\text {nd }}$ author: & $2^{\text {nd }}$ author: & $2^{\text {nd }}$ author: & $2^{\text {nd }}$ author: \\
\hline & $9 / 64(14.1 \%)$ & $8 / 66(12.1 \%)$ & $3 / 69(4.3 \%)$ & $10 / 64(15.6 \%)$ & $11 / 65(16.9 \%)$ \\
\hline & $\begin{array}{l}3^{\text {rd }} \text { author or } \\
\text { further: }\end{array}$ & $\begin{array}{l}3^{\text {rd }} \text { author or } \\
\text { further: }\end{array}$ & $\begin{array}{l}3^{\text {rd }} \text { author or } \\
\text { further: }\end{array}$ & $\begin{array}{l}3^{\text {rd }} \text { author or } \\
\text { further: }\end{array}$ & $\begin{array}{l}3^{\text {rd }} \text { author or } \\
\text { further: }\end{array}$ \\
\hline & $2 / 64(3.1 \%)$ & $5 / 66(7.6 \%)$ & $5 / 69(7.3 \%)$ & $7 / 64(10.9 \%)$ & 9/65 (13.9\%) \\
\hline $\begin{array}{c}\text { Number of Papers } \\
\text { With Citations }\end{array}$ & $32 / 64(50.0 \%)$ & $30 / 66(45.5 \%)$ & $30 / 69(43.5 \%)$ & $38 / 64(59.4 \%)$ & $43 / 65(66.1 \%)$ \\
\hline $\begin{array}{l}\text { Number of Papers } \\
\text { Without Citation } \\
\text { (but Located in } \\
\text { Databases) }\end{array}$ & $4 / 64(6.3 \%)$ & 6/66 (9.1\%) & $10 / 69(14.5 \%)$ & $10 / 64(15.6 \%)$ & $7 / 65(10.8 \%)$ \\
\hline $\begin{array}{l}\text { Number of Papers } \\
\text { Not in Citation } \\
\text { Indexes }\end{array}$ & 28/64 (43.7\%) & $30 / 66(45.5 \%)$ & $29 / 69$ (42.0\%) & $16 / 64(25.0 \%)$ & $15 / 65(23.1 \%)$ \\
\hline \multirow{8}{*}{$\begin{array}{l}\text { Distribution of } \\
\text { Citations Accord- } \\
\text { ing to Different } \\
\text { Databases }\end{array}$} & Total Citations: & Total Citations: & Total Citations: & Total Citations: & Total Citations: \\
\hline & 393 & 355 & 223 & 588 & 258 \\
\hline & WoK: & WoK: & WoK: & WoK: & WoK: \\
\hline & $138(35.1 \%)$ & $157(44.2 \%)$ & $66(29.6 \%)$ & $260(44.2 \%)$ & $111(43.0 \%)$ \\
\hline & GS: & GS: & GS: & GS: & GS: \\
\hline & $364(92.6 \%)$ & 325 (91.5\%) & $221(99.1 \%)$ & $532(90.0 \%)$ & $238(92.2 \%)$ \\
\hline & Scopus: & Scopus: & Scopus: & Scopus: & Scopus: \\
\hline & $187(47.6 \%)$ & $207(58.3 \%)$ & $81(36.3 \%)$ & $319(54.3 \%)$ & $148(51.4 \%)$ \\
\hline
\end{tabular}


TABLE 4. Journals with the Most Trainee Publications.

\begin{tabular}{lc}
\hline Journal & $\begin{array}{c}\text { Number of Trainee } \\
\text { Publications }\end{array}$ \\
\hline Romanian Journal of Bioethics & 34 \\
Developing World Bioethics & 23 \\
Indian Journal of Medical Ethics & 23 \\
Acta Bioethica & 19 \\
Revista Romana de Bioetica & 17 \\
PLoS Medicine & 14 \\
Lancet & 12 \\
African Journal of Medicine and Medical & 10 \\
Sciences & \\
\hline
\end{tabular}

setting and influencing policy. Consequently, the overall influence of the scholarly activity of trainees on practice and policy may be underestimated. This is a clear limitation of citation analysis as a measure of research impact. Annual reports from PIs were the exclusive source for trainee publication data, so the number of publications may be an underestimate if trainees failed to submit accurate and complete reports of their publications. Expert opinion was used to assess paper titles for classification as bioethics papers and this may have underestimated the number of papers.

The content of the papers regarding which ethical issues were addressed and whether the papers employed quantitative, qualitative, or conceptual approaches to bioethics was not examined. The database created for this study provides an opportunity for further analysis of these issues, which would be of interest to the bioethics community as it would permit examination of thematic content of papers and country-specific metrics.

While the literature on citation analysis of bioethics scholarship is relatively underdeveloped, particularly for training programs, we believe these data can contribute to future comparative studies and warrant the setting of benchmarks for productivity. The study results indicate that FIC trainees are productive in contributing to the bioethics literature, often as first authors, and these publications have been cited. The results indicate a body of scholarly literature is emerging from the FIC bioethics program, despite publication not being a major requirement of the training program. This indicates substantial added value. Trainees are clearly contributing to local and global scholarship as evidenced by contributions to national or regional bioethics journals as well as highimpact international journals. Ongoing support to build capacity in this field is desirable, with particular attention to fostering more trainees as first authors and achieving greater penetration of the non-English literature. Future studies should continue to explore the productivity and impact of FIC-sponsored scholarship and describe the content and approach of papers published by trainees. Other bioethics training programs may find utility in these methods for assessing the scholarly productivity and impact of their graduates.

\section{Best Practices}

Citation analysis is one useful but circumscribed approach to measure impact in bioethics scholarship from an ethics education program. Journal articles are only one type of scholarly writing respected in the bioethics field; however, they are more integrated with biomedical publication and, therefore, more likely to reach a broader audience regarding relevant research ethics topics which they address. Multiple scientific journal indexes need to be examined when conducting this type of bibliometric analysis in order to limit underrepresentation in bioethics paper citations for LMIC authors due to variable inclusion of bioethics journals, non-English journals, and online publications. Despite providing evidence of successful academic influence over time, lower impact factors and citation rates are common in small, specialized fields such as bioethics.

\section{Research Agenda}

While improvement was observed in the proportion of LMIC trainee publications in journals covered by the major citation indexes during the last decade, examination of the reasons why LMIC-authored publications continue to be underrepresented in bioethics literature may lead to remediable solutions. Research ethics graduate education programs may also benefit from research on the barriers and disincentives to first author publications by LMIC trainees. Of particular interest may be further examination of unique contribution in bioethics topic focus to the literature of the field as an expression of interests and primary concerns of LMIC bioethicists.

\section{Educational Implications}

Trainee research publication is not a primary objective of the research ethics training programs analyzed in this paper. However, many of the LMIC participants bring previously acquired academic scholarship skills as well as concerns regarding specific bioethics issues and processes relevant to research in their countries to their training experience, which can be explored through practicum projects supported by the programs. Ethics graduate-level education programs for LMIC academics and health professionals should consider how to strengthen ethics 
research methodology training and analytical writing skills of trainees to support expression of their unique perspectives, LMIC-specific data, and guidance to the growing global health research community.

\section{Acknowledgments}

The authors would like to expresses their sincere thanks to all the PIs in the International Research Ethics Education and Curriculum Development Award for their constructive and thoughtful feedback.

\section{Author Note}

Address correspondence to Ross Upshur: Professor, Department of Family and Community Medicine, University of Toronto, Room 678, 155 College Street, Toronto, Ontario, Canada M5T 3M7. Phone: 416-357-0663; Fax: 416-978-8299; E-MAIL: ross.upshur@gmail.com.

\section{Authors' Biographical Sketches}

Jonathan Fix is an undergraduate student at the University of Maryland-College Park. He collected and analyzed the trainee publication data and wrote the methods section as a summer intern at the Fogarty International Center.

Jere Odell is a Scholarly Communications Librarian and Liaison to the School of Public and Environmental Affairs at University Library at Indiana UniversityPurdue University Indianapolis (IUPUI). His main interests are in scholarly publishing, digital libraries, and equitable access to information. He contributed to the methods, literature review, and analysis and to the writing of the manuscript.

Barbara Sina is a Program Officer in the Division of International Training and Research, Fogarty International Center, National Institutes of Health, who manages the International Research Ethics Education and Curriculum Development awards. Her primary focus is building research capacity in low- and middleincome countries in neglected tropical diseases. She advised on data collection and analysis and contributed to the overall direction and writing of the manuscript.

Eric M. Meslin is the Director of the Indiana University Center for Bioethics, Associate Dean (Bioethics) at the IU School of Medicine, and Professor of Bioethics. He is the principal investigator of an FIC International Research Ethics Education and Curriculum Development program at Indiana University and Moi University in Kenya. His main interests are in global health ethics, research ethics, and science policy. He contributed to analysis of the data, writing of the manuscript, and approval of the final version.

Ken Goodman is Director, Bioethics Program in the Department of Medicine, University of Miami Medical School, and Co-Director of the University of Miami Ethics Programs. He is the principal investigator in the FIC International Research Ethics Education and Curriculum Development program at the University of Miami for Latin America. His research interests are in ethics and health informatics, ethics and epidemiology, and public health and research ethics. He contributed to analysis of the data, drafting of the manuscript, and approval of the final version.

Ross Upshur is a Professor in the Department of Family and Community Medicine and Dalla Lana School of Public Health at the University of Toronto, and the principal investigator of an FIC International Research Ethics Education and Curriculum Development master's degree program for trainees from Africa and South Asia. His main research interests in ethics are research ethics, public health ethics, and global health ethics. He conceived the idea for the paper and assisted in the data analysis and drafting of the manuscript.

\section{References}

$\rightarrow$ Baldwin, C., Hughes, J., Hope, T., Jacoby, R., \& Ziebland, S. (2003). Ethics and dementia: Mapping the literature by bibliometric analysis. International Journal of Geriatric Psychiatry, 18(1), 41-54.

Bauer, K., \& Bakkalbasi, N. (2005). An examination of citation counts in a new scholarly communication environment. D-Lib Magazine, 11(09). Retrieved from www.dlib.org/dlib/ september05/bauer/09bauer.html.

$\rightarrow$ Belinchon, I., Ramos, J. M., \& Bellver, V. (2007). Scientific production in bioethics in Sprain through MEDLINE. Gaceta Sanitaria, 21(5), 408-411. $\rightarrow$ Borry, P., Schotsmans, P., \& Dierickx, K. (2005). Developing countries and bioethical research. New England Journal of Medicine, 353(8), 852-853.

$\rightarrow$ Borry, P., Schotsmans, P., \& Dierickx, K. (2006a). How international is bioethics? A quantitative retrospective study. BMC Medical Ethics, 13(7), E1.

$\rightarrow$ Borry, P., Schotsmans, P., \& Dierickx, K. (2006b). Empirical research in bioethical journals: A quantitative analysis. Journal of Medical Ethics, 32(4), 240-245. 
$\rightarrow$ Cohen, C., Vianna, J. A., Battistella, L. R., \& Massad, E. (2008) Time variation of some selected topics in bioethical publications. Journal of Medical Ethics, 34(2), 81-84.

$\rightarrow$ DAGG, A. I., \& SeIDLE, T. K. (2004). Levels of citation of nonhuman animal studies conducted at a Canadian research hospital. Journal of Applied Animal Welfare Science, 7(3), 205-213.

Dorsch, J. L. (1997). BIOETHICSLINE use by medical students: Curriculum-integrated instruction and collection development implications. Bulletin of the Medical Library Association, 85(2), 147-153.

Dos Santos, M. F., \& De France, G. V. (2011). Bioethics and anesthesia: A reflexive study of reports published in the Brazilian Journal of Anesthesiology. Revista Brasileira de Anestesiologia, 61(1), 151-157.

Eiseman, E. (2003). The National Bioethics Advisory Commission: Contributing to public policy. Santa Monica, CA: Rand Corp.

$\rightarrow$ Garfield, E., \& Welljams-Dorof, A. (1990). The impact of fraudulent research on the scientific literature: The Stephen E. Breuning case. JAMA, 263(10), 1424-1426.

$\rightarrow$ Garnett, A., Whiteley, L., Piwowar, H., Rasmussen, E., \& ILLES, J. (2011). Neuroethics and fMRI: Mapping a fledgling relationship. PLoS One, 6(4), e18537.

Harzing, A. W., \& VAN der WAL, R. (2007). Google Scholar: The democratization of citation analysis. Ethics in Science and Environmental Politics, 8(1), 61-73.

$\rightarrow$ Hirsch, J. E. (2005). An index to quantify an individual's scientific research output. Proceedings of the National Academy of Sciences of the United States of America, 102(46), 16569-16572.

$\rightarrow$ Holm, S., \& Williams-Jones, B. (2006). Global bioethics: Myth or reality? BMC Medical Ethics, 7, E10.

$\rightarrow$ Hossne, W. S. (2011) Periódicos de bioética. ¿Hay muchos? ¿Hay pocos? ¿Cuál es la situación? Acta Bioethica, 17(1), 115-121.

$\rightarrow$ Jiang, L., Shen, J., Li, Y., Deng, S., Wu, T., Chen, B., ...ET Al. (2012). Subject, function, and trend in medical ethics research: A comparative study of Chinese and non-Chinese literature using bibliometrics. Journal of Evidence-Based Medicine, 5(2), 57-65. $\rightarrow$ Korpela, K. M. (2010). How long does it take for the scientific literature to purge itself of fraudulent material?: The Breuning case revisited. Current Medical Research and Opinion, 26(4), 843-847.

$\rightarrow$ Kulkarni, A. V., Aziz, B., Shams, I., \& Busse, J. W. (2009). Comparisons of citations in Web of Science, Scopus, and Google Scholar for articles published in general medical journals. JAMA, 302(10), 1092-1096.

$\rightarrow$ Lillquist, E., \& Green, S. (2010). The discipline dependence of citation statistics. Scientometrics, 84, 749-762.

Marques, K. B., De Sousa, P. S., \& Gimenez Galvao, M. T. (2006). Tendencies on the issue "ethics in health" in scientific production. Revista da Rede de Enfermagem do Nordeste, 7(3), 85-90.

$\rightarrow$ Neale, A. V., Dailey, R. K., \& Abrams, J. (2010). Analysis of citations to biomedical articles affected by scientific misconduct. Science and Engineering Ethics, 16(2), 251-261.

Neale, A. V., Northrup, J., Dailey, R., Marks, E., \& Abrams, J. (2007). Correction and use of biomedical literature affected by scientific misconduct. Science and Engineering Ethics, 13(1), 5-24.

Pizzani, L., DA Silva, R. C., \& Hossne, W. S. (2010). Análise bibliométrica dos 40 anos da produção científica em Bioética no Brasil e no mundo. Revista Bioethikos, 4(4), 453-460.

$\rightarrow$ Rietjens, J. A., Deschepper, R., Pasman, R., \& Deliens, L. (2012). Medical end-of-life decisions: Does its use differ in vulnerable patient groups? A systematic review and metaanalysis. Social Science and Medicine, 74(8), 1282-1287.

Soós, S. (2006). Current science and applied ethics, theories and practice: Mapping the field. Világosság, 5, 67-77.

$\rightarrow$ Steen, R. G. (2012). Retractions in the medical literature: How can patients be protected from risk? Journal of Medical Ethics, 38(4), 228-232.

Stepke, F. L. (2010). Acta Bioethica: Una década de historia. Acta Bioethica, 16(2), 115-118.

$\rightarrow$ Wendler, D. (2006). One-time general consent for research on biological samples. BMJ, 332(7540), 544-547.

$\rightarrow$ Zarzeczny, A., \& Caulfield, T. (2009). Emerging ethical, legal and social issues associated with stem cell research and the current role of the moral status of the embryo. Stem Cell Review, 5(2), 96-101. 